\title{
Three-Year Outcome of Very Low Birth Weight Infants in Conservatively Managed Premature Rupture of Membranes
}

\author{
Jun Sasahara*, Keisuke Ishii, Toshiko Kishimoto, Akiko Yamashita, Shusaku Hayashi, \\ Nobuaki Mitsuda \\ Department of Maternal Fetal Medicine, Osaka Medical Center and Research Institute for Maternal and Child \\ Health, Izumi, Japan \\ Email: ${ }^{*}$ sakch813@mch.pref.osaka.jp
}

Received 7 January 2015; accepted 21 January 2015; published 23 January 2015

Academic Editor: Yasam Kemal Akpak, Ankara Mevki Military Hospital, Turkey

Copyright (C) 2015 by authors and Scientific Research Publishing Inc.

This work is licensed under the Creative Commons Attribution International License (CC BY).

http://creativecommons.org/licenses/by/4.0/

\section{(c) (i) Open Access}

\begin{abstract}
Aim: To elucidate the outcome for very low birth weight infants delivered after preterm premature rupture of membranes (PPROM) managed conservatively, and to determine the prognostic value of perinatal factors for long-term outcome. Methods: Perinatal data were collected from medical records for singleton live-birth infants delivered between 1991 and 2008 after conservatively managed PPROM. Cases of congenital anomalies and chromosomal aberrations were excluded. Poor outcome was defined as a composite measure of death, neurological morbidity including cerebral palsy, or neurodevelopmental delay. Associations between perinatal factors and poor outcome at the corrected age of 3 were estimated using logistic regression analysis. Results: After the exclusion, 356 infants meeting the study criteria were identified, 26 cases were lost to follow-up, and 330 were eligible at 3 years. The mortality rate was $10 \%$ and the incidence of neurological morbidities was $12 \%$. Logistic regression analysis revealed gestational age at birth [adjusted odds ratio (aOR) 0.815], and five-minute Apgar scores (aOR 0.521) were independent predictors for poor outcome. Conclusion: When PPROM was managed conservatively, $22 \%$ of VLBW infants had a poor outcome at corrected age of 3 years. Early gestational age at birth and low Apgar scores were associated with poor outcome.
\end{abstract}

\footnotetext{
*Corresponding author.
}

How to cite this paper: Sasahara, J., Ishii, K., Kishimoto, T., Yamashita, A., Hayashi, S. and Mitsuda, N. (2015) Three-Year Outcome of Very Low Birth Weight Infants in Conservatively Managed Premature Rupture of Membranes. Open Journal of Obstetrics and Gynecology, 5, 70-78. http://dx.doi.org/10.4236/ojog.2015.51010 


\section{Keywords}

\section{Preterm Rupture of Membranes, Conservative Treatment, Neonatal Outcome}

\section{Introduction}

Preterm premature rupture of membranes (PPROM) in the second trimester is one of the main causes of subsequent early preterm birth [1] [2]. Consequently, it is the cause of considerable neonatal mortality and morbidity, mainly due to prematurity. Moreover, in very low birthweight (VLBW) preterm infants (weighing less than $1500 \mathrm{~g}$ ) both gestational age at birth and birth weight are related to neurodevelopmentally intact survival [3]. Although optimal management to improve long-term outcome remains undetermined in VLBW infants born after PPROM, conservative management is generally recommended with careful observation of maternal and fetal condition [4] [5]. However, particularly in second trimester PPROM, there can be a conflict between the benefit of prolonging gestational age in the anticipation of fetal growth and the increased chance of intrauterine infection and inflammation [6], which are closely related to PPROM and may also increase infant morbidity [4] [5].

The aim of this study was to evaluate the long-term outcome in VLBW infants delivered after the conservative management of PPROM, and to detect the perinatal prognostic factors for poor outcome.

\section{Materials and Methods}

A retrospective cohort study was performed at a single center. Subjects comprised VLBW singleton infants born after conservatively managed PPROM and delivered in our center between 1991 and 2008. This study was approved by the institutional review board at the Osaka Medical Center and Research Institute for Maternal and Child Health, Japan.

Gestational age was calculated on the basis of the last menstrual period as well as by crown-rump length on ultrasonography (at up to 12 weeks of gestational age). PPROM was diagnosed in the presence of either obvious leakage of amniotic fluid from the external os on sterile speculum examination or pooling of amniotic fluid in the vaginal cavity that showed a positive result on nitrazine testing or immunoassays detecting insulin-like growth factor-binding protein-1 [7]. Patients who had been diagnosed with PPROM were managed conservatively. In other words, prophylactic antibiotics, tocolytics, and betamethasone for inducing fetal lung maturation were given at the discretion of the attending obstetrician. Ampicillin-based antibiotics and tocolytics were administered with close monitoring of maternal and fetal condition but without a particular regimen. The decision to deliver was generally triggered by the presence of a non-reassuring fetal heart rate tracing or clinical findings of maternal infection. Generally, cesarean section was performed for non-cephalic presentation. All neonates were resuscitated immediately after birth by neonatal specialists and transferred to the neonatal intensive care unit (NICU) for subsequent management.

Perinatal factors assessed consisted of maternal and fetal factors. Maternal factors were: age, parity, history of cesarean section and preterm delivery ( $<37$ weeks of gestation), presence of cervical cerclage during present pregnancy, mode of delivery, usage of tocolytics, including intravenous beta-agonists and/or magnesium sulfate, maternal betamethasone administration and prophylactic usage of antibiotics, concomitant placental abruption and concomitant cord prolapse, latency from PPROM to delivery, maternal fever $>38^{\circ} \mathrm{C}$ at least one point between PPROM and delivery, and high inflammatory response within a week before delivery (maternal serum Creactive protein $(\mathrm{CRP})>2.0 \mathrm{mg} / \mathrm{dl}$ or white blood cell count $(\mathrm{WBC})>15,000 / \mathrm{mm}^{3}$ ). Maternal age (years old) was categorized as follows: less than 20; 20 to 30; 30 to 40; and 40 or more. Latency period (days) from PPROM to delivery was divided into four groups: less than 2; 2 to 9; 9 to 16; and 16 or more. We also recorded gestational age at PPROM and delivery, and histopathological evidence of severe chorioamnionitis (CAM) (grade 3, according to Blanc's criteria [8]). Five-minute Apgar scores were divided into the following three groups: Fetal factors were: neonatal birth weight, five-minute Apgar scores, infant gender, whether the neonate was light for gestational age (LGA), 3 or less; 4 to 6; and 7 or more. LGA was defined as less than the 10th percentile of birth weight for gestational age based on sex-specific birth weights for Japan [9].

Neurological development at 3 years of corrected age was measured using the Kyoto Scale of Psychological Development (K-test) [10], which is a Japanese standard test for evaluating neurodevelopmental progress and 
delay. The K-test is an individualized face-to-face test administered by experienced psychologists to assess a child's development in the following three areas: Postural-Motor; Cognitive-Adaptive; and Language-Social. In each of the three areas, the sum score is converted to a developmental age (DA), and an overall DA is also obtained. In this regard, however, cases which were clearly judged to be without disability by pediatricians were defined as having normal development, without use of the K-test.

The primary outcome was a composite measure of poor outcome, including gait deficits with cerebral palsy, neurodevelopmental delay corresponding to overall developmental quotient (DQ) lower than 70, and death before 3 years of corrected age. Odds ratios (ORs) and 95\% confidence intervals (CIs) were determined by univariate analysis and used to evaluate the influence of perinatal factors. A multiple logistic regression model for poor prognosis was also constructed using variables obtained by stepwise selection (significance level for entry into the model was $<0.20$ ). Reported p values are two-sided and analyses were performed using SPSS software version 20 (SPSS Inc., Chicago, IL).

\section{Results}

Figure 1 shows the flowchart for enrolled patients. We included 378 VLBW infants that were the product of singleton pregnancies with associated conservatively managed PPROM. Twenty-two patients were excluded from the analysis due to chromosomal abnormality $(n=4)$, congenital malformations $(n=6)$, and intrauterine death $(n=12)$. Among the final study cohort of 356 infants, 26 cases were lost to follow-up; therefore, 330 were eligible for follow-up at 3 years of corrected age.

Table 1 describes the prenatal characteristics. Tocolytics such as ritodrine hydrochloride and magnesium

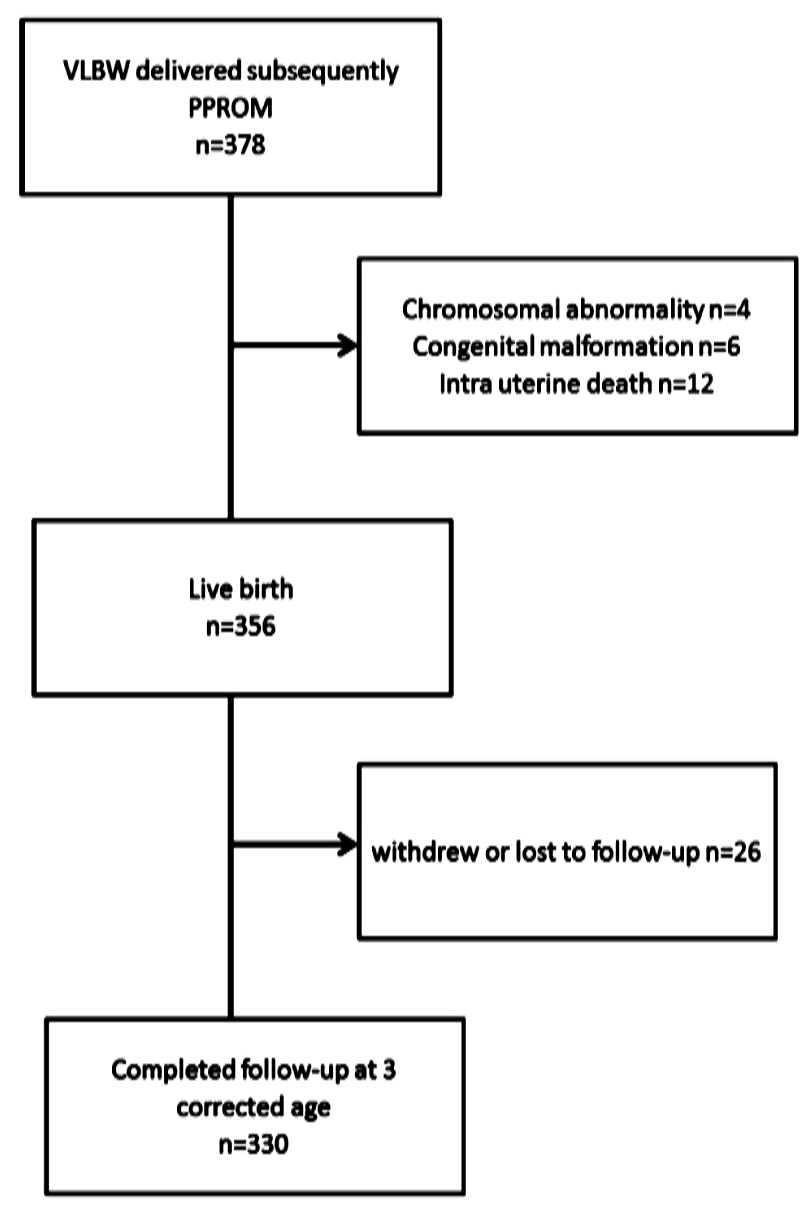

Figure 1. Flowchart of enrolled very low birth weight infants delivered after preterm premature rupture of membranes managed conservatively. 
Table 1. Baseline maternal characteristics and prenatal clinical information.

\begin{tabular}{|c|c|}
\hline Valuables $(\mathrm{n}=330)$ & Median (range) or $\mathrm{n}(\%)$ \\
\hline Maternal age, y & $30.1(18.9-42.4)$ \\
\hline$<20$ & $7(2.1)$ \\
\hline $20-30$ & $148(44.8)$ \\
\hline $30-40$ & $168(50.9)$ \\
\hline $40<$ & $7(2.1)$ \\
\hline Multipara & $186(56.4)$ \\
\hline Previous preterm delivery & $33(17.7)$ \\
\hline Cervical cerclage & $43(13.0)$ \\
\hline Cesarean section & $175(53.0)$ \\
\hline Usage of tocolytics & 310 (93.9) \\
\hline Ritodrine chloride, & 309 (93.6) \\
\hline Magnesium sulfate & $168(50.9)$ \\
\hline Betamethasone & $161(48.6)$ \\
\hline Antibiotics & $290(87.9)$ \\
\hline Abruption placenta & $19(5.8)$ \\
\hline Cord prolapse & $10(3.0)$ \\
\hline Latency period of PROM, days & $4(0-69)$ \\
\hline Less than 2 & $104(31.5)$ \\
\hline 2 to 9 & $136(41.2)$ \\
\hline 9 to 16 & $36(10.9)$ \\
\hline 16 or more & $54(16.4)$ \\
\hline Excessive fever $\left({ }^{\circ} \mathrm{C}\right)^{\mathrm{a}}$ & 35 (10.6) \\
\hline $\mathrm{CRP}^{\mathrm{a}}>2.0 \mathrm{mg} / \mathrm{dl}$ & $165(50.0)$ \\
\hline $\mathrm{WBC}^{\mathrm{b}}>15,000 / \mathrm{mm}^{3}$ & $93(28.2)$ \\
\hline
\end{tabular}

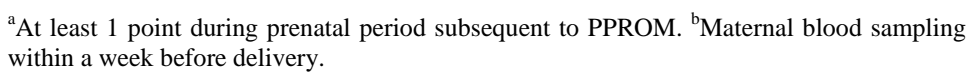

sulfate were administered in approximately $94 \%$ of cases. The latency period from PPROM to delivery was widely distributed; the median latency period was 4 (range, 0 - 69) days and pregnancy continued for more than 2 days after PPROM in $68.5 \%$ of cases.

Table 2 shows the perinatal and neonatal information. PPROM occurred at a median of $25+5$ (range, $12+5$ $31+6$ ) weeks of gestation and median gestational age at delivery was $26+6$ (range, $22+3-34+2$ ) weeks. Median birth weight was 894 (range, 412 - 1496) grams. Five-minute Apgar scores of less than 3 occurred in 8.2\% of cases, while umbilical artery $\mathrm{pH}$ less than 7.0 was noted in only $1.8 \%$ of cases.

Table 3 shows the mortality and neurodevelopmental outcome among the 330 infants at corrected age 3 . The mortality rate was $10.0 \%$ (33/330), comprising 21 (6.7\%) cases of early neonatal death within the first 7 days of life, 3 (0.9\%) of neonatal death between 7 to 28 days of life, and 9 (2.7\%) of infant death after 28 days of age. Neurodevelopmental delay with low overall DQ (<70) was diagnosed in $39(11.8 \%)$ cases. Eight $(2.4 \%)$ children were diagnosed with cerebral palsy with gait deficit, and all of these also had low DQ. Consequently, there were 72 cases $(21.8 \%)$ of poor outcome at 3 years of corrected age.

Table 4 demonstrates the results of multivariable logistic regression analysis. After adjusting for the con- 
Table 2. Pregnancy outcome and neonatal information.

\begin{tabular}{lc}
\hline \multicolumn{1}{c}{ Valuables $(\mathrm{n}=330)$} & Median (range) or $\mathrm{n}(\%)$ \\
\hline Vaginal delivery & $155(47.0)$ \\
Gestational age at PPROM ${ }^{\mathrm{a}}\left(\right.$ week $\left.^{+ \text {day }}\right)$ & $25+5\left(12^{+5}-31^{+6}\right)$ \\
Gestational age at birth $\left(\right.$ week $\left.^{+ \text {day }}\right)$ & $26+6\left(22^{+3}-34^{+2}\right)$ \\
Birth weight (grams) & $892(412-1496)$ \\
UA ${ }^{\mathrm{b}} \mathrm{pH}$ & $7.348(6.716-7.552)$ \\
$<7.000$ & $6(1.8)$ \\
Apgar score at 5 minutes (pts) & $8(0-10)$ \\
3 or less & $27(8.2)$ \\
4 to 6 & $76(23.0)$ \\
7 or more & $227(68.8)$ \\
Male infant & $184(55.8)$ \\
Light for gestational age & $39(11.8)$ \\
Funisitis & $214(64.8)$ \\
Histopathological CAM & $131(39.7)$ \\
\hline
\end{tabular}

${ }^{\mathrm{a}}$ Preterm premature rupture of membranes. ${ }^{\mathrm{b}}$ Umbilical artery. ${ }^{\mathrm{c}}$ Histopathological chorioamnionitis (Grade 3, according to the criteria by Blanc. [8]).

Table 3. The incidence of adverse outcomes at 3 years of corrected age in very low birthweight infants delivered after preterm premature rupture of membranes managed conservatively.

\begin{tabular}{cc}
\hline Valuables $(\mathrm{n}=330)$ & $\mathrm{n}(\%)$ \\
\hline Mortality & $33(10.0)$ \\
$\mathrm{DQ}^{\mathrm{a}}<70$ without $\mathrm{CP}^{\mathrm{b}}$ & $31(9.4)$ \\
$\mathrm{DQ}<70$ with CP & $8(2.4)$ \\
Composite poor outcome & $72(21.8)$ \\
\hline
\end{tabular}

a Developmental Quotient. 'bait deficits with cerebral palsy.

Table 4. Multiple logistic regression analysis of predictors for outcomes at 3 years of corrected age in very low birthweight infants delivered after preterm premature rupture of membranes managed conservatively.

\begin{tabular}{ccccc}
\hline \multicolumn{1}{c}{ Valuables } & ${\text { Crude } \mathrm{OR}^{\mathrm{a}}\left(95 \% \mathrm{CI}^{\mathrm{b}}\right)}$ & P value & Adjusted OR (95\%CI) & P value \\
\hline Gestational age at birth & $0.739(0.651-0.838)$ & $<0.001$ & $0.815(0.707-0.939)$ & 0.005 \\
Apgar score at 5 minutes $^{\mathrm{c}}$ & $0.355(0.241-0.523)$ & $<0.001$ & $0.521(0.331-0.820)$ & 0.005
\end{tabular}

${ }^{\mathrm{a}}$ Odds ratio. ${ }^{\mathrm{b}}$ Confidence interval. ${ }^{\mathrm{c}}$ Apgar score at 5 minutes were subdivided into 3 or less, 4 to 6 , and 7 or more.

founding variables, gestational age at birth (adjusted OR, 0.815; 95\% CI, $0.707-0.939$; $\mathrm{P}$ value $=0.005$ ) and Apgar scores at five minutes (adjusted OR, 0.521; 95\% CI, $0.331-0.820$; P value $=0.005$ ) were found to be associated with the composite poor outcome.

\section{Discussion}

This study revealed the long-term outcome of VLBW infants from pregnancies in which PPROM was managed 
conservatively. Approximately $22 \%$ of eligible cases had a poor outcome at 3 years. These findings were similar to those of previous studies for VLBW infants, regardless of the presence or absence of PPROM. Neonatal morbidity, including respiratory distress syndrome, sepsis, and intraventricular hemorrhage, is reported to be associated with PPROM. However, in the present study, which focused only on cases of PPROM, the prevalence of long-term adverse outcome in VLBW infants was similar to that in previous reports of preterm infants, regardless of the presence or absence of PPROM [11]-[14]. Herefore, our results could not reveal an obvious negative effect of PPROM itself on the long-term outcome of the surviving infants.

Gestational age at birth and birth weight are generally considered strong predictors of neonatal mortality and morbidity in preterm infants [11]. Some previous studies have also shown that survival rate among VLBW infants increased gradually with increasing gestational age, regardless of the presence of rupture of membranes [11]-[13] [15]. In the present study, concerning the long-term prognosis of infants delivered after PPROM, multivariate logistic analysis also showed that gestational age at birth was significantly associated with poor prognosis at 3 years of age.

A previous systematic review of PPROM occurring between 28 and 34 weeks reported that the neonatal death rate was significantly higher in cases with intentional early delivery compared with those that were expectantly managed [16]. Therefore, expectant management seems to be commonly chosen for PPROM cases prior to 32 weeks of gestation unless there are conditions that threaten the life of either fetus or mother, such as fetal distress, placental abruption, or severe clinical infection. However, few studies have comprehensively evaluated the long-term outcome and perinatal prognostic factors in cases of PPROM managed expectantly. One previous study showed that mortality at 2 years was $19 \%$ in 53 cases of PPROM before 28 weeks that were managed expectantly, but a possible limitation of this report was the relatively small patient sample [17]. On the other hand, the present study analyzed 330 consecutive cases and showed that mortality rate at 3 years was only $10 \%$, which may have strong implications for the management of mid-trimester PPROM from the point of view of long-term prognosis.

Recently, due to their convenience, Apgar scores have been used worldwide to evaluate neonatal status just after birth [18]. Although five-minute Apgar score is thought to be a reliable index for later neurologic or developmental disability [19], caution is necessary when interpreting Apgar scores for VLBW infants. These premature infants mostly need immediate resuscitation, and the physician might therefore assign the Apgar scores retrospectively, raising the possibility that the five-minute Apgar score may not precisely reflect the situation at the time [20] [21]. Nonetheless, VLBW infants delivered after PPROM and with low Apgar scores should be observed carefully during follow-up.

Umbilical artery pH less than 7.00 is thought to be associated with neurological outcome [22]. However, our results could not detect the significance of umbilical artery $\mathrm{pH}$ as a prognostic factor.

A meta-analysis of studies that elucidated the association between chorioamnionitis and cerebral palsy demonstrated that clinical chorioamnionitis, diagnosed based on maternal fever and maternal leukocytosis, was a significant risk factor for cerebral palsy [23]. However, our results did not show an association between clinical or histopathological chorioamnionitis and adverse outcome, including 8 cases of cerebral palsy at corrected age 3. This discrepancy may be due to the difference at age at evaluation and relatively small number of cases with cerebral palsy. Other studies have found that severe histological chorioamnionitis was associated with perinatal death, but those authors have suggested that this factor might not have a strong direct effect on long-term neurodevelopmental outcome [24] [25]. Adversely, severe pathological chorioamnionitis was also not related to outcome in the present study. Recently, fetal inflammatory response, as defined by elevated fetal plasma interleukin, has been recognized as a risk factor for severe neonatal morbidity [26] [27], however, the present study did not examine serum inflammatory makers.

Abnormal fetal heart rate in labor resulting from umbilical cord compression is observed more frequently in PPROM than when the membranes are intact [28]. Cesarean section might be beneficial in early preterm PPROM, and in breech presentation, particularly before 30 weeks of gestational age [29] [30], however, optimal mode of delivery remains uncertain between 30 and 34 weeks [31] [32]. In the present cohort, $47 \%$ of deliveries were vaginal, and delivery mode was not significantly associated with outcome. Therefore, considering the maternal complications associated with cesarean section, the method of delivery should be decided after careful consideration.

The present study revealed that the prevalence of placental abruption and umbilical cord prolapse were 5.8\% and $3.0 \%$, respectively, which seems consistent with previous reports [33] [34]. The rarity of these complica- 
tions might explain why they were not significant predictors of adverse outcome in the present study.

It is important to acknowledge that our study has several limitations. First, $18.6 \%$ of children were determined to have normal development, despite the fact that neurodevelopmental status was not evaluated by the K-test. This could result in bias; however, caregivers of these children were questioned in detail by a specialist in pediatrics on aspects of health including psychomotor development. Second, this study was retrospectively performed on a large sample of subjects recruited during a 20-year period. Therefore, the consequent variations in management of PPROM might have influenced the results.

\section{Conclusion}

In conclusion, more than one-fifth of VLBW infants delivered after conservative management of PPROM showed poor outcome at 3-year follow-up. Poor outcome appeared to be related to early gestational age at birth and low five-minute Apgar score. These results emphasize that the conservative management of PPROM, in anticipation of the prolongation of gestation, might improve the long-term prognosis of infants.

\section{Acknowledgements}

Our sincere thanks to Keisuke Ishii, Toshiko Kishimoto, Akiko Yamashita, Shusaku Hayashi, and Nobuaki Mitsuda for their positive cooperation on this work.

\section{Disclosure}

No author has any potential conflict of interest.

\section{References}

[1] Goldenberg, R.L., Culhane, J.F., Iams, J.D. and Romero, R. (2008) Epidemiology and Causes of Preterm Birth. The Lancet, 371, 75-84. http://dx.doi.org/10.1016/S0140-6736(08)60074-4

[2] Mathews, T.J. and MacDorman, M.F. (2010) Infant Mortality Statistics from the 2006 Period Linked Birth/Infant Death Data Set. National Vital Statistics Reports: From the Centers for Disease Control and Prevention, National Center for Health Statistics. National Vital Statistics System, 58, 1-31.

[3] Tyson, J.E., Parikh, N.A., Langer, J., Green, C. and Higgins, R.D. for National Institute of Child Health and Human Development Neonatal Research Network (2008) Intensive Care for Extreme Prematurity—Moving beyond Gestational Age. The New England Journal of Medicine, 358, 1672-1681. http://dx.doi.org/10.1056/NEJMoa073059

[4] Eastman, N.J. and Deleon, M. (1955) The Etiology of Cerebral Palsy. American Journal of Obstetrics and Gynecology, 69, 950-961.

[5] Murphy, D.J., Sellers, S., MacKenzie, I.Z., Yudkin, P.L. and Johnson, A.M. (1995) Case-Control Study of Antenatal and Intrapartum Risk Factors for Cerebral Palsy in Very Preterm Singleton Babies. The Lancet, 346, 1449-1454. http://dx.doi.org/10.1016/S0140-6736(95)92471-X

[6] Gibbs, R.S. and Duff, P. (1991) Progress in Pathogenesis and Management of Clinical Intraamniotic Infection. American Journal of Obstetrics and Gynecology, 164, 1317-1326. http://dx.doi.org/10.1016/0002-9378(91)90707-X

[7] Lockwood, C.J., Wein, R., Chien, D., Ghidini, A., Alvarez, M. and Berkowitz, R.L. (1994) Fetal Membrane Rupture Is Associated with the Presence of Insulin-Like Growth Factor-Binding Protein-1 in Vaginal Secretions. American Journal of Obstetrics and Gynecology, 171, 146-150. http://dx.doi.org/10.1016/0002-9378(94)90461-8

[8] Blanc, W.A. (1981) Pathology of the Placenta, Membranes, and Umbilical Cord in Bacterial, Fungal, and Viral Infections in Man. Monographs in Pathology, 22, 67-132.

[9] Itabashi, K., Miura, F., Uehara, R. and Nakamura, Y. (2014) New Japanese Neonatal Anthropometric Charts for Gestational Age at Birth. Pediatrics International, 56, 702-708.

[10] Koyama, T., Osada, H., Tsujii, H. and Kurita, H. (2009) Utility of the Kyoto Scale of Psychological Development in Cognitive Assessment of Children with Pervasive Developmental Disorders. Psychiatry and Clinical Neurosciences, 63, 241-243. http://dx.doi.org/10.1111/j.1440-1819.2009.01931.x

[11] Fanaroff, A.A., Stoll, B.J., Wright, L.L., Carlo, W.A., Ehrenkranz, R.A., Stark, A.R., et al. (2007) Trends in Neonatal Morbidity and Mortality for Very Low Birth Weight Infants. American Journal of Obstetrics and Gynecology, 196, 147.e1-147.e8.

[12] Lemons, J.A., Bauer, C.R., Oh, W., Korones, S.B., Papile, L.A., Stoll, B.J., et al. (2001) Very Low Birth Weight Out- 
comes of the National Institute of Child Health and Human Development Neonatal Research Network, January 1995 through December 1996. NICHD Neonatal Research Network. Pediatrics, 107, e1. http://dx.doi.org/10.1542/peds.107.1.e1

[13] Horbar, J.D., Carpenter, J.H., Badger, G.J., Kenny, M.J., Soll, R.F., Morrow, K.A., et al. (2012) Mortality and Neonatal Morbidity among Infants 501 to 1500 Grams from 2000 to 2009. Pediatrics, 129, 1019-1026. http://dx.doi.org/10.1542/peds.2011-3028

[14] Kono, Y., Mishina, J., Yonemoto, N., Kusuda, S. and Fujimura, M. (2011) Outcomes of Very-Low-Birth Weight Infants at 3 Years of Age Born in 2003-2004 in Japan. Pediatrics International: Official Journal of the Japan Pediatric Society, 53, 1051-1058. http://dx.doi.org/10.1111/j.1442-200X.2011.03480.x

[15] Pristauz, G., Bauer, M., Maurer-Fellbaum, U., Rotky-Fast, C., Bader, A.A., Haas, J. and Lang, U. (2008) Neonatal Outcome and Two-Year Follow-Up after Expectant Management of Second Trimester Rupture of Membranes. International Journal of Gynecology \& Obstetrics: The Official Organ of the International Federation of Gynecology and Obstetrics, 101, 264-268. http://dx.doi.org/10.1016/j.ijgo.2007.12.007

[16] Al-Mandeel, H., Alhindi, M.Y. and Sauve, R. (2013) Effects of Intentional Delivery on Maternal and Neonatal Outcomes in Pregnancies with Preterm Prelabour Rupture of Membranes between 28 and 34 Weeks of Gestation: A Systematic Review and Meta-Analysis. The Journal of Maternal-Fetal and Neonatal Medicine: The Official Journal of the European Association of Perinatal Medicine, 26, 83-89. http://dx.doi.org/10.3109/14767058.2012.718388

[17] Farooqi, A., Holmgren, P.A., Engberg, S. and Serenius, F. (1998) Survival and 2-Year Outcome with Expectant Management of Second-Trimester Rupture of Membranes. Obstetrics \& Gynecology, 92, 895-901. http://dx.doi.org/10.1016/S0029-7844(98)00287-7

[18] Apgar, V. (1953) A Proposal for a New Method of Evaluation of the Newborn Infant. Current Researches in Anesthesia \& Analgesia, 32, 260-267.

[19] Jepson, H.A., Talashek, M.L. and Tichy, A.M. (1991) The Apgar Score: Evolution, Limitations, and Scoring Guidelines. Birth, 18, 83-92. http://dx.doi.org/10.1111/j.1523-536X.1991.tb00065.X

[20] Lee, H.C., Subeh, M. and Gould, J.B. (2010) Low Apgar Score and Mortality in Extremely Preterm Neonates Born in the United States. Acta Paediatrica, 99, 1785-1789. http://dx.doi.org/10.1111/j.1651-2227.2010.01935.x

[21] Casey, B.M., McIntire, D.D. and Leveno, K.J. (2001) The Continuing Value of the Apgar Score for the Assessment of Newborn Infants. The New England Journal of Medicine, 344, 467-471. http://dx.doi.org/10.1056/NEJM200102153440701

[22] Flidel-Rimon, O. and Shinwell, E.S. (2007) Neonatal Aspects of the Relationship between Intrapartum Events and Cerebral Palsy. Clinics in Perinatology, 34, 439-449. http://dx.doi.org/10.1016/j.clp.2007.06.001

[23] Wu, Y.W. and Colford Jr., J.M. (2000) Chorioamnionitis as a Risk Factor for Cerebral Palsy: A Meta-Analysis. JAMA: The Journal of the American Medical Association, 284, 1417-1424. http://dx.doi.org/10.1001/jama.284.11.1417

[24] van Hoeven, K.H., Anyaegbunam, A., Hochster, H., Whitty, J.E., Distant, J., Crawford, C., et al. (1996) Clinical Significance of Increasing Histologic Severity of Acute Inflammation in the Fetal Membranes and Umbilical Cord. Pediatric Pathology \& Laboratory Medicine: Journal of the Society for Pediatric Pathology, 16, 731-744.

[25] Andrews, W.W., Cliver, S.P., Biasini, F., Peralta-Carcelen, A.M., Rector, R., Alriksson-Schmidt, A.I., et al. (2008) Early Preterm Birth: Association between in Utero Exposure to Acute Inflammation and Severe Neurodevelopmental Disability at 6 Years of Age. American Journal of Obstetrics and Gynecology, 198, 466.e1-466.e11.

[26] Gomez, R., Romero, R., Ghezzi, F., Yoon, B.H., Mazor, M. and Berry, S.M. (1998) The Fetal Inflammatory Response Syndrome. American Journal of Obstetrics and Gynecology, 179, 194-202. http://dx.doi.org/10.1016/S0002-9378(98)70272-8

[27] Lee, S.E., Romero, R., Jung, H., Park, C.W., Park, J.S. and Yoon, B.H. (2007) The Intensity of the Fetal Inflammatory Response in Intraamniotic Inflammation with and without Microbial Invasion of the Amniotic Cavity. American Journal of Obstetrics and Gynecology, 197, 294.e1-294.e6.

[28] Waters, T.P. and Mercer, B.M. (2009) The Management of Preterm Premature Rupture of the Membranes Near the Limit of Fetal Viability. American Journal of Obstetrics and Gynecology, 201, 230-240. http://dx.doi.org/10.1016/j.ajog.2009.06.049

[29] Demol, S., Bashiri, A., Furman, B., Maymon, E., Shoham-Vardi, I. and Mazor, M. (2000) Breech Presentation Is a Risk Factor for Intrapartum and Neonatal Death in Preterm Delivery. European Journal of Obstetrics \& Gynecology and Reproductive Biology, 93, 47-51. http://dx.doi.org/10.1016/S0301-2115(00)00246-3

[30] Mousiolis, A., Papantoniou, N., Mesogitis, S., Baglatzi, L., Baroutis, G. and Antsaklis, A. (2012) Optimum Mode of Delivery in Gestations Complicated by Preterm Premature Rupture of the Membranes. The Journal of Maternal-Fetal and Neonatal Medicine: The Official Journal of the European Association of Perinatal Medicine, 25, 1044-1049. http://dx.doi.org/10.3109/14767058.2011.614659 
[31] Brown, L., Karrison, T. and Cibils, L.A. (1994) Mode of Delivery and Perinatal Results in Breech Presentation. American Journal of Obstetrics and Gynecology, 171, 28-34. http://dx.doi.org/10.1016/S0002-9378(94)70073-7

[32] Riskin, A., Riskin-Mashiah, S., Lusky, A. and Reichman, B., in Collaboration with the Israel Neonatal Network (2004) The Relationship between Delivery Mode and Mortality in Very Low Birthweight Singleton Vertex-Presenting Infants. BJOG: An International Journal of Obstetrics \& Gynaecology, 111, 1365-1371. http://dx.doi.org/10.1111/j.1471-0528.2004.00268.x

[33] Lewis, D.F., Robichaux, A.G., Jaekle, R.K., Salas, A., Canzoneri, B.J., Horton, K., et al. (2007) Expectant Management of Preterm Premature Rupture of Membranes and Nonvertex Presentation: What Are the Risks? American Journal of Obstetrics and Gynecology, 196, 566.e1-566.e5, discussion 566.e5-566.e6.

[34] Markhus, V.H., Rasmussen, S., Lie, S.A. and Irgens, L.M. (2011) Placental Abruption and Premature Rupture of Membranes. Acta Obstetricia et Gynecologica Scandinavica, 90, 1024-1029. http://dx.doi.org/10.1111/j.1600-0412.2011.01224.x 
Scientific Research Publishing (SCIRP) is one of the largest Open Access journal publishers. It is currently publishing more than 200 open access, online, peer-reviewed journals covering a wide range of academic disciplines. SCIRP serves the worldwide academic communities and contributes to the progress and application of science with its publication.

Other selected journals from SCIRP are listed as below. Submit your manuscript to us via either submit@scirp.org or Online Submission Portal.
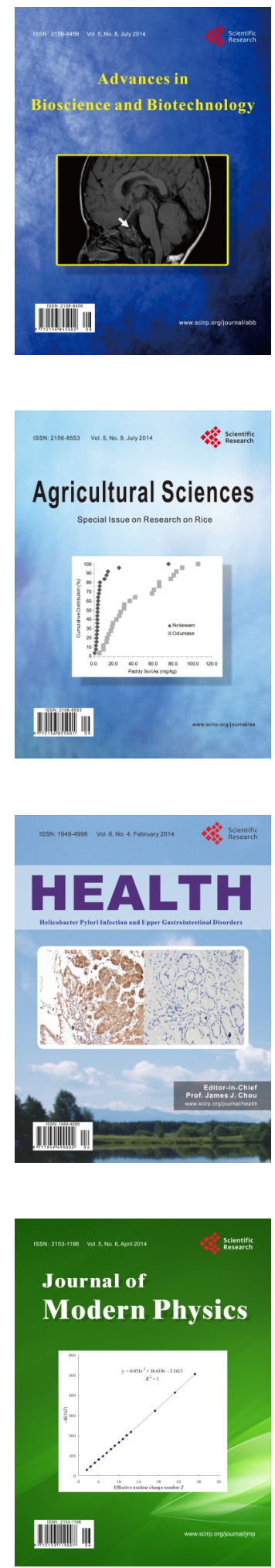
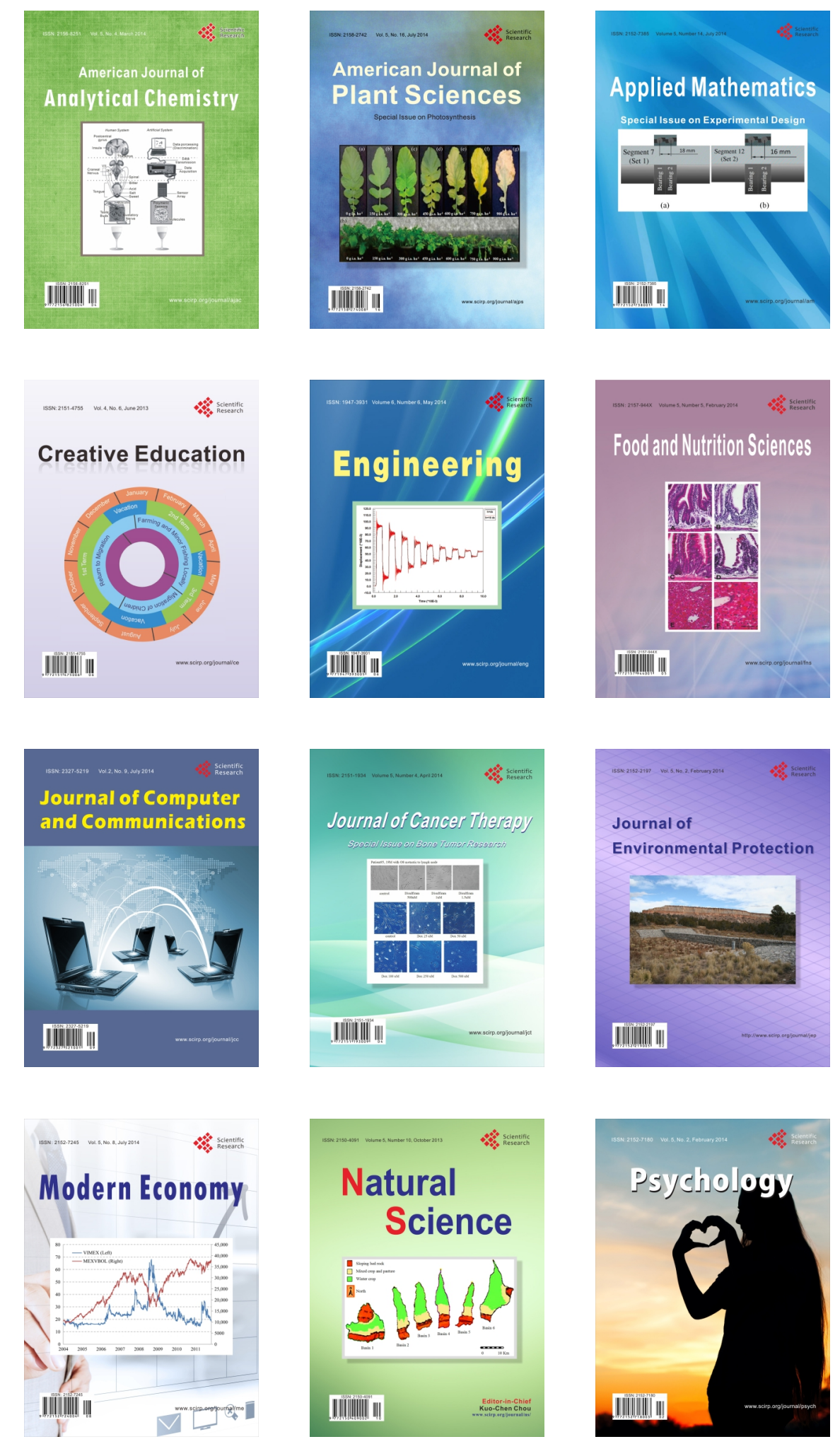